\title{
Heart Rate Variability During an Internal Family Systems Approach to Self-Forgiveness
}

\author{
Kyle W. Eaton, Thomas M. Ferrari*
}

Kyle W. Eaton, Thomas M. Ferrari*

Department of Foundational Medical Studies, Oakland University William Beaumont School of Medicine, Rochester, MI 48309, UNITED STATES OF AMERICA.

*Correspondence

Thomas M. Ferrari, Ph.D.

OUWB School of Medicine

Department of Foundational Medical Studies-586 Pioneer Dr. Rochester MI 48309-4482.

Phone: 248-370-3887

Email: mbferrari@oakland.edu

History

- Submission Date: 26-03-2020;

- Review completed: 03-05-2020

- Accepted Date: 28-05-2020

DOI : 10.5530/ijcep.2020.7.2.14

Article Available online

http://www.ijcep.org

Copyright

(C) 2020 Phoog.Net. This is an openaccess article distributed under the terms of the Creative Commons Attribution 4.0 International license.

\begin{abstract}
Background and Aim: Self-recrimination is a stress-inducing cognitive process, so there is a strong need for evidence-based effective self-forgiveness interventions. Most individuals, and particularly those in professions with high occupational stress, can suffer damaging bouts of self-recrimination, leading to depression, burnout and/or suicide. Unfortunately, useful frameworks for developing self-forgiveness skills appear limited. Methods: We designed a guided imagery session, based on the internal family systems therapeutic model, to facilitate the process of self-forgiveness. We used surveys and ECG recordings to 1) determine the effectiveness of the self-forgiveness imagery, 2) collect baseline psychometric data on forgiveness, particularly self-forgiveness, 3) collect ECG data during baseline, self-critical rumination and self-forgiveness periods and 4) correlate the psychometric and physiological data. Results: Together, our outcomes indicate the intervention is highly effective and that the self-forgiveness state produces high parasympathetic tone. Conclusion: A single, relatively short guided imagery session can facilitate significant self-forgiveness which is associated with reduced physiological stress.

Key words: Occupational Stress, Medical Error, Forgiveness, Well-Being, Autonomic Nervous System, Heart Rate Variability.
\end{abstract}

\section{INTRODUCTION}

The practice of self-forgiveness is more challenging than forgiving others, partly since it requires acknowledging oneself as the transgressor, ${ }^{[1,2]}$ and it may be particularly challenging in high stakes professions where errors in decision-making and action can lead to injury or death. In health care, the financial and emotional costs of medical error are high, ${ }^{[3,4]}$ and physicians struggle with the idea of self-forgiveness. ${ }^{[5]}$ The chronic stress, high rates of depression and burnout among students, residents and physicians ${ }^{[6-9]}$ motivated our development of an intervention to reduce self-condemnation and promote self-forgiveness.

Forgiveness is beneficial to psychological and physical health in numerous ways. ${ }^{[10-18]}$ The overall physical health benefits of forgiveness appear to correlate with a significantly smaller increase in cardiovascular reactivity when compared to angry rumination. ${ }^{[1,13,16,19-21]}$ Indicators of cardiovascular function not only show strain on the cardiovascular system; they also reflect the stress response controlled by the autonomic nervous system (ANS). Heart rate variability (HRV) is a strong indicator of morbidity when low and increased longevity when high; it has been strongly correlated with cardiovascular and psychological health. ${ }^{[22-28]}$ HRV provides real-time information on ANS adjustments for physiological and psychological real and perceived needs, ${ }^{[29-32]}$ and

Cite this article: Eaton KW, Ferrari TM. Heart Rate Variability During an Internal Family Systems Approach to Self-Forgiveness. Int J Clin Exp Physiol. 2020;7(2):52-7. can be interpreted as both a dispositional trait that reflects a person's adaptability to situations ${ }^{[33]}$ as well as a situation-dependent indicator of cardiovascular reactivity.

While other-forgiveness has received considerable attention, the psychology and physiology of selfforgiveness has lagged behind. ${ }^{[34]}$ However, studies on self-forgiveness have increased recently, ${ }^{[21,35]}$ driven by a need to understand the basic psychology of selfforgiveness and the possible physical and emotional health benefits. When assessing their transgressions, people can experience self-condemnation and stress; this negative self-evaluation is strongly supported by the 'inner critic' or judge. ${ }^{[36-38]}$

In the internal family systems (IFS) approach, ${ }^{[39]}$ the conceptual framework is based on differentiating the Self from the other parts, or subpersonalities, of the mind. For example, in IFS therapy, individuals are introduced to the 'inner critic' or judge that is producing self-condemnation. This attack is directed at a young or 'innocent' part that has made errors and experienced trauma and as a result it often becomes isolated from the rest of the system. In IFS therapy, primary goals include guiding individuals into re-connecting with the exile(s) and discovering the positive intention of each part. The ultimate goal of IFS therapy is balancing the input and roles of all the parts, as orchestrated by Self. ${ }^{[39]}$ For this study,

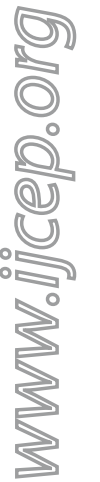


we used IFS-based imagery and hypothesized that self-forgiveness would increase and that increases in SF would be positively correlated with increased HRV.

\section{MATERIALS AND METHODS}

\section{Participants}

Data were collected for 24 participants (18 Female) from a midwestern U.S. university campus (study approved by the OU IRB). The average age was 27.7 years old ( $S D=11.5$; range $18-61$ years). Sufficient power was estimated from previous studies of similar design with statistically significant results. ${ }^{[16]}$

\section{Measures}

After giving informed consent, participants completed the 14-item Perceived Stress Scale (PSS), ${ }^{[40]}$ 38-item Multidimensional Anger Inventory (MAI), ${ }^{[41]}$ 18-item Heartland Forgiveness Scale (HFS), ${ }^{[42]}$ 17-item State Self-Forgiveness Scale (SSFS), ${ }^{[43]}$ and 4-item Tendency to Forgive scale (TTFS). ${ }^{[44]}$ The pre-survey order was PSS, MAI, HFS, SSFS, TTFS; the post-survey order was HFS, SSFS, TTFS. The Heartland Forgiveness Scale ${ }^{[42]}$ is an 18 -item self-report measure assessing dispositional forgiveness across three subscales: the HFS self-subscale, the HFS others subscale and the HFS situations subscale. The 6-item HFS self-subscale is the primary focus in this report because the main intervention component targeted self-forgiveness. A sum score was calculated for the HFS self-subscale with higher responses indicating increased self-forgiveness. Internal consistency for the HFS self-subscale was adequate at both pre-intervention (Cronbach's $\mathrm{a}=.78$ ) and postintervention (Cronbach's $\mathrm{a}=.69$ ).

\section{Electrophysiology}

After completing informed consent and the pre-survey, participants were seated in a small conference room and outfitted with electrocardiography (ECG), electromyography (EMG) and respiratory recording equipment using the Power Lab T26 system from AD Instruments (Dunedin, New Zealand). For a 3-lead ECG, reusable clamp style electrodes were placed over each prepared area (inside of both wrists and inside of left ankle). For the EMG, two small disposable $\mathrm{Ag} / \mathrm{AgCl}$ electrodes were applied 2-3 $\mathrm{mm}$ apart above the eyebrow and vertically aligned with the pupil (i.e. frontalis). For recording respiratory parameters, a piezo-electric belt transducer was placed just below the solar plexus. Participants sat quietly for the next few minutes while stable connections/clean recordings were established and verified. At this point the experimenter began the $40 \mathrm{~min}$ audio and left the participant alone in the room.

\section{Guided Imagery}

The audio, while a seamless narrative of guided imagery from the participant's viewpoint, consisted of 7 epochs each designed to evoke a particular state and last long enough $(\sim 5 \mathrm{~min})$ for adequate data analysis (full transcript, appendix A); in brief, the epochs were as follows: Epoch A, baseline 1; Epoch B, guided relaxation; Epoch C, baseline 2; Epoch $\mathrm{D}$, transgression recall/self-recrimination; Epoch E, inner critic; Epoch F, authentic self; Epoch G, self-forgiveness. In Epoch D, the participant was asked to recall an incident they self-identified as a transgression, i.e. having behaved wrongly or made a mistake, with an intensity of around 5/10. In Epoch E, participants are introduced to their inner critic, who normally attacks both self and others for making mistakes and the critic is then asked to 'step aside'. In Epoch F, the participant is introduced to the IFS concept of self and begins the process of granting forgiveness to the exhile/innocent from self, which culminates in Epoch G. At the end of the audio and recording session, the headphones, electrodes and respiratory belt were removed and the subject completed three postsurvey scales (HFS, SSFS and TTFS). In the post survey, an additional item was included: "As I consider what I did that was wrong, I have forgiven myself" on a 10 point Likert scale $1=$ not at all and $10=$ completely.

\section{ECG Analysis}

All 3 raw data traces (ECG, EMG and respiratory) were visually inspected for motion artifacts (particularly evident on the ECG) and 5 min periods free of such artifact were selected. HR and HRV analysis was conducted using Lab Chart v8.0.9 and the AD Instruments HRV analysis module. Time domain HRV analysis, e.g. SDRR, is appropriate if there are at least 5 min of continuous data; ${ }^{[45,46]}$ however, measures of TP and VLF from short recordings are physiologically ambiguous and not recommended (Task Force). Therefore, we report here the changes and correlations in SDRR, LF, HF and LF/HF ratios using absolute units. Maximum frequency for the spectrum analysis was $0.5 \mathrm{~Hz}, 500$ frequencies, analyzed in $10 \mathrm{~ms}$ bins with a pRR threshold of $50 \mathrm{~ms}$ and SDARR averaging of $300 \mathrm{sec}$. The beat classification included an RR interval of 500-1500 ms and complexity of 1-1.5 and ectopics were excluded from the analysis.

\section{Statistical Analysis of Data}

All data (psychometric and ECG-derived) were exported to excel for further analysis and statistical tests using SPSS.

\section{RESULTS}

Prior to conducting the main analyses, the data were checked to ensure that parametric assumptions were met. Normality was assessed via skewness and kurtosis values as well as the Shapiro-Wilk test. These preliminary results all indicate that the HFS and the HFS self-subscale met acceptable criteria for normality (e.g., HFS self-subscale preintervention; $\mathrm{W}=0.970, p=0.666$ ). Because parametric assumptions were met, a paired samples $t$-test was conducted to compare the HFS self- subscale pre versus post intervention (Table 1). Scores preintervention $(\mathrm{M}=26.17, \mathrm{SD}=6.23)$ were significantly lower than scores post-intervention $(\mathrm{M}=31.29, \mathrm{SD}=4.56)$ at the $p<0.05$ level; $\mathrm{t}(23)=$ $-6.188, p<0.001$.

To examine HRV across the epochs, a one-way repeated measures ANOVA was utilized. Further, because three time points were of particular interest (B, F and $G)$, sphericity was examined via the

Table 1: Forgiveness Scales Score Changes.

$\begin{array}{ccccc} & & \text { Pre } & \text { Post } & \text { *p } \\ \text { HFS - self } & \text { M } & 26.17 & 31.29 & 2.6 \mathrm{E}-6 \\ & \text { SD } & 6.23 & 4.56 & \\ \text { HFS - other } & \text { M } & 59.83 & 64.13 & .008 \\ & \text { SD } & 8.68 & 7.60 & \\ \text { HFS - total } & \text { M } & 86.00 & 95.42 & .00008 \\ & \text { SD } & 13.13 & 11.61 & \\ \text { SSFS } & \text { M } & 50.63 & 67.25 & 7.4 \mathrm{E}-8 \\ & \text { SD } & 11.47 & 8.93 & \\ \text { TTFS } & \text { M } & 15.42 & 18.04 & .0005 \\ & \text { SD } & 3.87 & 3.64 & \\ \end{array}$

HFS $=$ Heartland Forgiveness Scale ${ }^{[42]}$ SSFS $=$ State Self-Forgiveness Scale ${ }^{[43]}$ TTFS $=$ Tendency To Forgive Scale ${ }^{[44]}$

* Paired two-tailed $t$-tests 
Mauchly's test. The results suggest that the sphericity assumption was violated indicating that the variances of the differences were not equal, $\mathrm{x}^{2}(2)=10.448, p<0.05$; therefore, Greenhouse-Geisser corrected tests were examined $(\varepsilon=0.726)$. The results suggest statistically significant differences between the three epochs; $\mathrm{F}(1.45,33.38)=3.984, p<0.05$ and post-hoc tests (with Bonferroni corrections) were assessed to further examine which epochs significantly differed from each other. Post-hoc comparisons revealed that $\mathrm{HRV}$ scores on Epoch $\mathrm{A}(\mathrm{M}=56.22, \mathrm{SD}=$ 22.20) were significantly lower $(p<0.05)$ than Epoch $\mathrm{B}(\mathrm{M}=68.38$, $\mathrm{SD}=29.83)$ and marginally significantly different from Epoch $\mathrm{F}(\mathrm{M}=$ $67.11, \mathrm{SD}=28.06 ; p=0.054)$. Alternatively, there was not a significant HRV difference between Epoch $\mathrm{B}(\mathrm{M}=68.38, \mathrm{SD}=29.83)$ and Epoch $\mathrm{F}(\mathrm{M}=67.11, \mathrm{SD}=28.06)(p=0.999)$.

\section{Intervention and Forgiveness Scale Scores}

Participant other-forgiveness and self-forgiveness scores increased significantly after the IFS-based intervention $\left(p=0.00008,7.4 \mathrm{E}^{-8}\right.$ and 0.0005 for the HFS, SSFS and TTFS, respectively; see Table 1). Similarly, in response to the post-survey statement 'As I consider what I did that was wrong, I have forgiven myself', which was anchored at 1 $=$ not at all and $10=$ completely, the average score was $7.6(\mathrm{SD}=1.2)$. The SSFS pre and HFS self pre scores correlated with one another $(\mathrm{R}=$ $0.451, p=0.027$ ), although the SSFS pre is not correlated with the TTFS pre, indicating that self and other-forgiveness may be different internal constructs. HFS self and HFS other subscores were also significantly correlated $(\mathrm{R}=0.538, p=0.0067)$.

\section{Electrocardiography}

There was no significant change in HR between the different epochs for any participant (One-way ANOVA, $n=25, \mathrm{~d}_{f}=6$, between group p-level = 99.99). There were no significant correlations between HR and MAI, nor between HR and any of the forgiveness scales. The change in LF between initial baseline and self-forgiveness (A-G LF delta) was inversely related to the HFS self-delta $(\mathrm{R}=-0.48, \mathrm{p}=0.0176)$. While SDRR in all epochs was not significantly correlated to any of the forgiveness scales, it is worth noting that for both epochs D and G the correlations to SSFS delta and the SUM Fscales self-delta fell between p values of 0.05-0.1, suggesting significance may have been achieved with a larger population.

\section{HRV - Correlations with Epochs}

When compared to both baselines (Epochs A and C), SDRR was significantly higher at Epochs B, F and G (e.g. A vs B, $p=0.003$, see Figure 1A). This same pattern held for HRV total power as well. For LF, all epochs were significantly positively correlated with one another, with only a small but significant increase in epoch B as compared to the baselines (e.g. LF A vs B, p = 0.027). No other trend or pattern for LF was apparent. For HRV HF, all epochs were again significantly positively correlated, with only a significant difference between epochs A and B $(p=0.00035)$; there were no significant changes thereafter. For LF/HF there was an increase from epoch $A$ to $B$ followed by a decrease from $B$ to $C$ such that these first three epochs were not correlated. However, all subsequent epochs (D-G) were significantly positively correlated with one another with a trend of increase during the forgiveness process (Figure 1B). Notably, there was a very high correlation between epochs $F$ and $\mathrm{G}$ for the $\mathrm{LF} / \mathrm{HF}$ ratio $\left(\mathrm{R}=0.96, p<1.1 \mathrm{E}^{-14}\right)$.

\section{DISCUSSION}

\section{Participants and Measures}

We drew from a suburban university campus and medical school and there appeared to be a significant self-selection gender bias, given that only 6 of 24 participants were male. It will be interesting to determine if this represents a true gender bias in terms of interest in self-forgiveness and if so, whether different recruitment approaches might encourage male enrollment.

In the pre-survey results, we found that higher anger scores were associated with a lower tendency to forgive - an early discovery in forgiveness research. ${ }^{[47-49]}$ Our results also suggested that higher stress lowers the tendency to forgive, also seen previously. Taken together, these

Table 2: Descriptives and Pearson's Correlations.

\begin{tabular}{|c|c|c|c|c|c|c|c|c|c|}
\hline & 1 & 2 & 3 & 4 & 5 & 6 & 7 & 8 & 9 \\
\hline $\begin{array}{c}\text { 1. Pre- } \\
\text { Intervention } \\
\text { HFS }\end{array}$ & - & & & & & & & & \\
\hline $\begin{array}{l}\text { 2. Post- } \\
\text { Intervention } \\
\text { HFS }\end{array}$ & .76 & - & & & & & & & \\
\hline 3. Epoch A & -.05 & -.08 & - & & & & & & \\
\hline 4. Epoch B & .04 & -.01 & $.81^{* *}$ & - & & & & & \\
\hline 5. Epoch C & -.20 & -.08 & $.64^{* *}$ & $.58^{* *}$ & - & & & & \\
\hline 6. Epoch D & -.24 & -.10 & $.64^{* *}$ & $.55^{* *}$ & $.69^{* *}$ & - & & & \\
\hline 7. Epoch E & -.09 & -.02 & $.61^{* *}$ & $.53^{* *}$ & $.67^{* *}$ & $.83^{* *}$ & - & & \\
\hline 8. Epoch F & -.12 & .02 & $.68^{* *}$ & $.49^{*}$ & $.63^{* *}$ & $.87^{* *}$ & $.78^{* *}$ & - & \\
\hline 9. Epoch G & -.22 & -.02 & $.70^{* *}$ & $.49^{*}$ & $.72^{* *}$ & $.89^{* *}$ & $.78^{* *}$ & $.88^{* *}$ & - \\
\hline \#Mean & 26.17 & 31.29 & 56.22 & 68.38 & 58.29 & 61.24 & 59.54 & 67.12 & 64.23 \\
\hline $\begin{array}{l}\text { \#Standard } \\
\text { Deviation }\end{array}$ & 6.23 & 4.56 & 22.20 & 29.83 & 23.61 & 21.22 & 22.73 & 28.06 & 21.00 \\
\hline
\end{tabular}


confirmatory observations suggest our study population was not skewed and was producing normative responses. There were no significant correlations between the PSS or MAI scores with the difference scores for any of the forgiveness scales; i.e. the degree of granted self-forgiveness was not correlated with state stress or anger - an encouraging finding.

\section{Internal Family Systems (IFS) Intervention}

The IFS-based intervention was extremely effective at facilitating selfforgiveness, as evidenced by increases in all three forgiveness scales and the high score for the additional SSFS post-survey question. This is a most welcome result, as it indicates this intervention may have great utility for helping those in high stakes, i.e. high occupational stress, environments. However, it is important to note the limitation that participants selfselected to be in the study and knew forgiveness was the focus; it will be important to determine if naïve participants respond similarly.

Given the significance differences between the other-forgiveness versus self-forgiveness pre versus post $t$-tests, it may be that these two forms of forgiveness are different internal constructs. The data, however, are somewhat conflicting. For example, the SSFS, a self-forgiveness scale, was not correlated with the TTFS, an other-forgiveness scale, whereas the SSFS and HFS self-subscales did correlate with one another. On the other hand, the HFS self and HFS other subscale scores were significantly correlated. We can envision three possible explanations for increases in both other and self-forgiveness, even though the intervention targeted self-forgiveness. First, granting forgiveness - to self or other - may create a generalized high state forgiveness. Second, the intervention instructs participants to grant forgiveness to themselves in the same manner as they would others; this prompt may have been sufficient to raise other-forgiveness thoughts and feelings that carried over into the post-survey period. Third and perhaps most intriguing, is the idea that there is no self-forgiveness - that it cannot occur in isolation with just a single entity. Forgiveness requires one who grants and one who accepts, forgiveness; self-forgiveness involves both forgiveness-seeking and selfreferential forgiveness-granting. ${ }^{[21]}$ So perhaps all forms are actually 'other'-forgiveness. In the IFS model, the 'self' grants forgiveness to the exile - it is by design dyadic. In future, it will be interesting to compare different forgiveness frameworks to determine if self-forgiveness can be achieved without a parts or subpersonalities approach.

\section{Psychometric and ECG Correlations}

We hypothesized the self-forgiveness process should reduce negative feelings and promote beneficial cardiovascular responses similar to those found in other-forgiveness research. ${ }^{[13,16,17,19,20,50]} \mathrm{HRV}$, as measured by SDRR and LF/HF ratio, increased significantly during guided relaxation and then dropped back to baseline during the periods of cognitive perseveration. These periods included recalling the transgression, recognition of the inner critic and introduction to the concept of self and parts in the psyche. Notably, HRV increased significantly in the last two epochs, during which participants are guided to identify with self and grant forgiveness to an exiled, innocent part. This suggests that identifying with self and granting forgiveness to oneself are almost as beneficial as direct guided relaxation. This is consonant with a large literature showing self-regulating practices (e.g. meditation, mindfulness, MBSR, yoga, qigong, tai chi, etc.), which increase activity in neural structures associated with agency and self, are associated with high HRV and increases in subjective wellness and lower stress. By contrast, those with low HRV are characterized by self-regulatory deficits including poor attention control, ineffective emotion regulation and behavioral inflexibility. ${ }^{[1,52]}$ Importantly, individual differences in HRV can be observed during resting baseline periods and appear to be relatively stable over time. ${ }^{[53]}$
That higher LF/HF positively correlated with MAI suggests that trait anger results in a higher degree of sympathetic tone, as has been observed elsewhere. ${ }^{[54]}$ In particular, it was interesting that the highest correlation was in the last two epochs, while individuals were connecting with self and attempting SF. It is important to note that many have suggested that the LF component represents both sympathetic and vagal influences. ${ }^{[45,46,55-57]}$ On the other hand, use of the LF band and the LF/HF ratio as sympathetic indices has been questioned, regardless of adjustment for total power ${ }^{[58-63]}$ However, general consensus is that activity in the HF band is considered to clearly represent vagal tone, whereas the LF band reflects both sympathetic and parasympathetic activity and may also be affected by other factors, such as diurnal variations. ${ }^{[45,46,64]}$ Regardless of the underlying physiological drivers, perhaps the most important take-away from our results is that the LF/HF ratio in epochs $\mathrm{F}$ and $\mathrm{G}$ was similar to epoch B. That is, connecting to self and granting selfforgiveness appeared, by this measure, to be as robust as guided imagery specifically directed towards promoting relaxation.

A somewhat different type of state, inferred rather than subjectively expressed-flexibility, behavioral regulation or readiness to react to the environment-has been related to higher HF-HRV ${ }^{[65,66]}$ Engagement in virtually any task typically reduces $\mathrm{HF}-\mathrm{HRV},{ }^{[67]}$ which interestingly we saw in epochs D-E but not F-G. Conversely, HF-HRV increased during epoch $\mathrm{B}$, guided relaxation, consistent with suggestions that high amplitude HF-HRV is associated with a positive mood, absence of negative affect and an alert readiness to engage with the physical and social environment. ${ }^{[68]}$

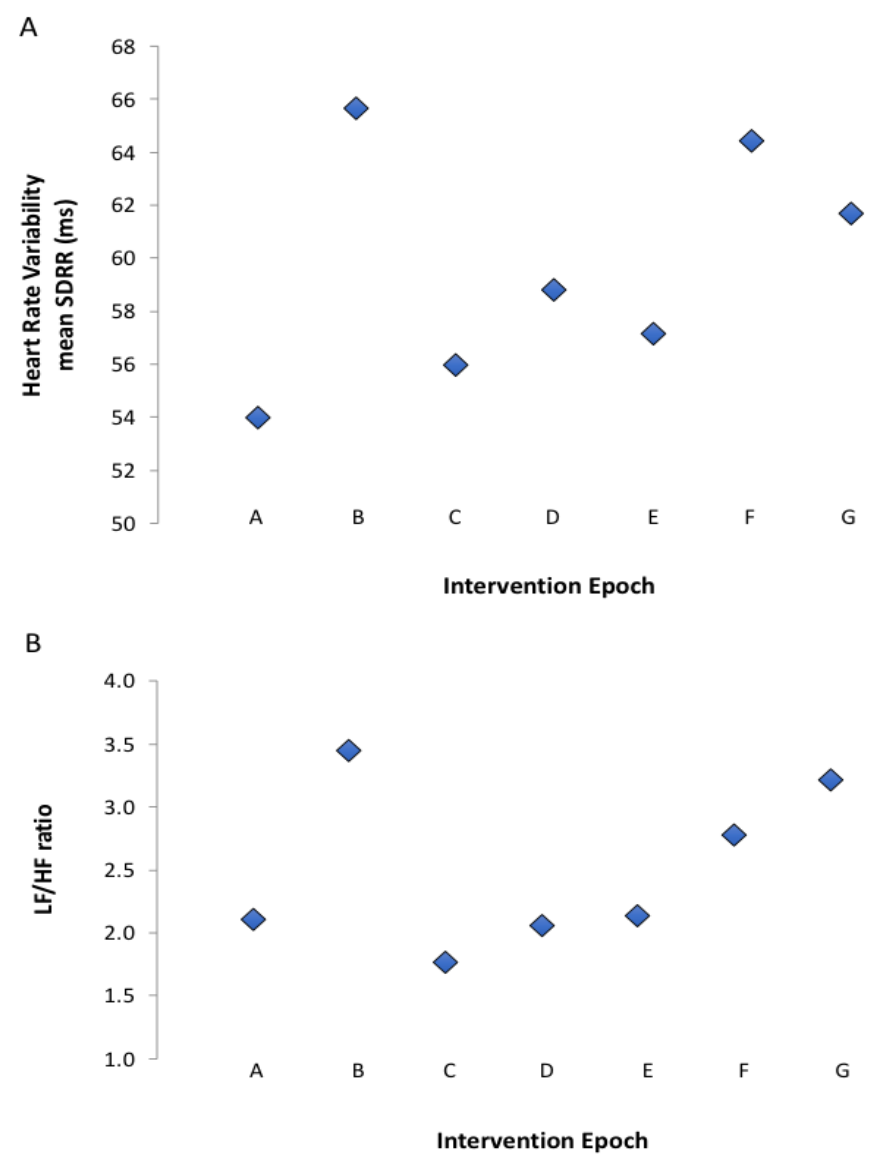

Figure 1A: HRV measured as mean SDRR during each epoch of the IFS-based guided imagery. The values in $\mathrm{B}, \mathrm{F}$ and $\mathrm{G}$ are not statistically different from one another.

Figure 1B: HRV as measured with the LF/HF ratio. 


\section{Limitations and Future Directions}

As noted above, our study participants were educated and, presumably, interested in forgiveness. Whether this intervention would work for naïve, or even oppositional, participants is unknown. Another limitation was ignorance of the transgression experience, it was totally unspecified except for intensity; it may have occurred recently or further in the past, involved intimate relationships or task failure, conflicted with or coincided with worldview, etc. Future studies would either need to specify types of transgressions, or include post-intervention interviews to address this issue. We also did not assess any affective dimensions after the intervention; while the parsimonious inference is that participants experienced relief and increased positive affect, as seen in a similar study ${ }^{[21]}$ these were not measured. Relatedly, it is unknown how much positive benefit was derived from connecting with self, versus setting aside the critic, versus embracing and forgiving the exile/innocent. Lastly, our pilot study included only three simple recordings (3-lead ECG, a single EMG and single belt plethysmography). It would be very interesting to examine the neural correlates of self-forgiveness via EEG and neuroimaging techniques.

\section{CONCLUSION}

Our guided imagery intervention, based on internal family systems (IFS), was highly effective in facilitating self-forgiveness as measured by 3 different survey instruments. Collectively, the cardiovascular data indicate the self-forgiveness state is correlated with high parasympathetic tone. Self-forgiveness thus appears to have immediate psychological and physiological health benefits and, if practiced regularly could also confer long-term cardioprotective benefits. This intervention could be an important resource for those exposed to high-stakes chronic occupational stress, particularly where perceived error and selfrecrimination compound negative affective states (e.g. health care, law enforcement, aviation safety, etc.).

\section{ACKNOWLEDGEMENT}

The authors thank Dr. Virgil Zeigler-Hill for consultation and advice on the psychology of self; Michelle Jankowski and Daniel Gildner for statistical analysis; ADInstruments for technical support; and the Oakland University IRB for helpful suggestions. We are also grateful for the volunteer research participants, the IFS work of Richard C. Schwartz PhD, and the service of James P Sisley† MA LMFT PLLC, to whom this work is dedicated. This research, part of OUWB graduation requirements (K.W.E.), did not receive any specific funding from the public, commercial, or not-for-profit sectors.

\section{CONFLICT OF INTEREST}

The authors have no financial or other conflicts of interest to disclose.

\section{ABBREVIATIONS}

ANS: Autonomic Nervous System; HRV: Heart Rate Variability; IFS: Internal Family Systems; PSS: Perceived Stress Scale; MAI: Multidimensional Anger Inventory; HFS: Heartland Forgiveness Scale; SSFS: State Self-Forgiveness Scale; TTFS: Tendency to Forgive scale.

\section{REFERENCES}

1. Bauer L, Duffy J, Fountain E, Halling S, Holzer M, Jones E, et al. Exploring selfforgiveness. J Relig Health. 1992;31:149-60.

2. Macaskill A, Maltby J, Day L. Forgiveness of Self and Others and Emotional Empathy. J Soc Psychol. 2002;142(5):663-5.

3. Anderson J. After the error, then what? The emotional impact of errors on clinicians. J Am Acad Phys. 2011;24(12):71-2.

4. Waterman AD, Garbutt J, Hazel E, Dunagan WC, Levinson W, Fraser VJ, et al.
The emotional impact of medical errors on practicing physicians in the United States and Canada. Jt Comm J Qual Patient Saf. 2007;33(8):467-76.

5. Plews-Ogan M, May N, Owens J, Ardelt M, Shapiro J, Bell SK. Wisdom in Medicine: What Helps Physicians After a Medical Error?. Acad Med. 2016;91(2):23341.

6. Dyrbye L, Shanafelt T. A narrative review on burnout experienced by medical students and residents. Med Educ. 2016;50(1):132-49.

7. Kothari R, Sharma S, Bokariya P. Stress, Stressors and Undergraduate Students: A Mini-Review. Int J Clin Exp Physiol. 2018;5(3):114-9.

8. Kuhn CM, Flanagan EM. Self-care as a professional imperative: Physician burnout, depression and suicide. Can J Anaesth. 2017;64(2):158-68.

9. Rothenberger DA. Physician Burnout and Well-Being: A Systematic Review and Framework for Action. Dis Colon Rectum. 2017;60(6):567-76.

10. Ross SR, Hertenstein MJ, Wrobel TA. Maladaptive correlates of the failure to forgive self and others: Further evidence for a two-component model of forgiveness. J Pers Assess. 2007;88(2):158-67.

11. Semenec SC. The relationship of self and other-forgiveness to interpersonal stress reactivity and recovery. Psych-Dissert. 2008;13.

12. Toussaint LL, Owen AD, Cheadle A. Forgive to live: Forgiveness, health and longevity. J Behav Med. 2012;35(4):375-86.

13. Larsen BA, Darby RS, Harris CR, Nelkin DK, Milam PE, Christenfeld NJ. The immediate and delayed cardiovascular benefits of forgiving. Psychosom Med. 2012;74(7):745-50

14. Friedberg JP, Suchday S, Shelov DV. The impact of forgiveness on cardiovascular reactivity and recovery. Int J Psychophysiol. 2007;65(2):87-94.

15. Lawler $K A$, Younger JW, Piferi $R L$, Jobe $R L$, Edmondson $K A$, Jones $W H$. The unique effects of forgiveness on health: An exploration of pathways. J Behav Med. 2005;28(2):157-67

16. Witvliet CVO, Ludwig TE, Vander LKL. Granting forgiveness or harboring grudges: Implications for emotion, physiology and health. Psychological Sci. 2001;12(2):117-23.

17. Witvliet CVO, McCullough ME. Forgiveness and health: A review and theoretical exploration of emotion pathways. In: Altruism and health: Perspectives from empirical research. Oxford: Oxford University Press. 2007;259-76.

18. Worthington EL, Wade NG, Hoyt WT. Positive Psychological Interventions for Promoting Forgiveness: History, Present Status and Future Prospects. The Wiley Blackwell handbook of positive psychological interventions. John Wiley and Sons. 2014

19. Lawler KA, Kline KA, Adlin RF, Wilcox ZC, Craig FW, Krishnamoorthy JS, et al. Psychophysiological correlates of individual differences in patterns of hemodynamic reactivity. Int J Psychophysiol. 2001;40(2):93-107.

20. Lawler KA, Younger JW, Piferi RL, Billington $E$, Jobe $R$, Edmondson $K$, et al. $A$ change of heart: Cardiovascular correlates of forgiveness in response to interpersonal conflict. J Behav Med. 2003;26(5):373-93.

21. DaSilva SP, Witvliet CVO, Riek B. Self-forgiveness and forgiveness-seeking in response to rumination: Cardiac and emotional responses of transgressors. $J$ Pos Psych. 2017; 12(4):362-72.

22. Fox NA, Porges SW. The relation between neonatal heart period patterns and developmental outcome. Child Dev. 1985;56:28-37.

23. Zulfiqar $U$, Jurivich $D A, G a o W$, Singer $\mathrm{DH}$. Relation of high heart rate variability to healthy longevity. Am J Cardiol. 2010;105(8):1181-5.

24. Ernst G. Heart-Rate Variability-More than Heart Beats?. Front Public Health 2017;5:240

25. Huston JM, Tracey KJ. The pulse of inflammation: Heart rate variability, the cholinergic anti-inflammatory pathway and implications for therapy. J Intern Med. $2011 ; 269(1): 45-53$

26. Montano N, Porta A, Cogliati C, Costantino G, Tobaldini E, Casali KR, et al. Heart rate variability explored in the frequency domain: $A$ tool to investigate the link between heart and behavior. Neurosci Biobehav Rev. 2009;33(2):71-80.

27. Thayer JF, Yamamoto SS, Brosschot JF. The relationship of autonomic imbalance, heart rate variability and cardiovascular disease risk factors. Int J Cardiol. 2010;141(2):122-31.

28. Jarczok MN, Jarczok M, Mauss D, Koenig J, Li J, Herr RM, et al. Autonomic nervous system activity and workplace stressors: A systematic review. Neurosci Biobehav Rev. 2013;37(8):1810-23.

29. Althaus M, Mulder LJ, Mulder G, Roon AMV, Minderaa RB. Influence of respiratory activity on the cardiac response pattern to mental effort. Psychophysiol. 1998;35(4):420-30.

30. Appelhans BM, Luecken LJ. Heart rate variability and pain: Associations of two interrelated homeostatic processes. Biol Psych. 2008;77(2):174-82.

31. Hjortskov N, Rissén D, Blangsted AK, Fallentin N, Lundberg U, Søgaard K. The effect of mental stress on heart rate variability and blood pressure during computer work. Euro J Appl Physiol. 2004;92(1-2):84-9.

32. Segerstrom SC, Nes LS. Heart rate variability reflects self-regulatory strength, effort and fatigue. Psych Sci. 2007;18(3):275-81.

33. Thayer JF, Hansen AL, Saus-Rose E, Johnsen BH. Heart rate variability, prefrontal neural function and cognitive performance: The neurovascular integration perspective on self-regulation, adaptation and health. Ann Behav Med. 
2009;37(2):141-53

34. Hall JH, Fincham FD. Self-Forgiveness: The Stepchild of Forgiveness Research. J Soc Clin Psych. 2005;24(5):621-37.

35. Woodyatt L, Worthington L. Orientation of psychology of self-forgiveness. Handbook of the psychology of self-forgiveness. Springer International Publishing. 2017;3-16

36. Elliott JE. Use of anthetic dialogue in eliciting and challenging dysfunctional beliefs. J Cog Psychother. 1992;6(2):137-43.

37. Brown B. Soul without shame: A guide to liberating yourself from the judge within. Shambhala Publications. 1998.

38. Gilbert $\mathrm{P}$, Irons $\mathrm{C}$. Focused therapies and compassionate mind training for shame and self-attacking. Compassion: Conceptualizations, Research and use in Psychotherapy. 2005;263-325

39. Schwartz RC. Internal family systems therapy. Guilford Press. $2^{\text {nd }}$ ed. 1997.

40. Cohen S, Kamarck T, Mermelstein R. A global measure of perceived stress. J Health Soc Behav. 1983;24(4):385-96.

41. Siegel JM. The multidimensional anger inventory. J Pers Soc Psychol. 1986;51(1):191.

42. Thompson LY, Snyder CR, Hoffman L. Heartland forgiveness scale. J Pers. 2005;73:313-59

43. Wohl MJ, DeShea L, Wahkinney RL. Looking within: Measuring state selfforgiveness and its relationship to psychological well-being. Can J Behav Sci. 2008;40(1):1-10.

44. Brown RP. Measuring individual differences in the tendency to forgive: Construct validity and links with depression. Pers Soc Psychol Bull. 2003;29(6):75971.

45. Berntson GG, Thomas BJ, Eckberg DL, Grossman P, Kaufmann PG, Malik M et al. Heart rate variability: Origins, methods and interpretive caveats. Psychophysiology. 1997;34(6):623-48.

46. Malik M. Heart rate variability. Ann Noninvas Electrocardiol. 1996;1:151-81.

47. Enright RD, Coyle CT. Researching the process model of forgiveness with in psychological interventions. Dimensions of forgiveness: Psychological research and theological perspectives. Philadelphia: Templeton Foundation Press. 1998;139-61.

48. Worthington EL. Dimensions of forgiveness: A research approach. Templeton Foundation Press. 1998;368

49. Barber L, Maltby J, Macaskill A. Angry memories and thoughts of revenge: The relationship between forgiveness and anger rumination. Personality and Individual Differences. 2005;39(2):253-62

50. Worthington EL, Witvliet CVO, Pietrini P, Miller AJ. Forgiveness, health and well-being: A review of evidence for emotional versus decisional forgiveness, dispositional forgivingness and reduced unforgiveness. J Behav Med. 2007;30(4):291-302

51. Applehans BM, Luecken LJ. Attentional processes, anxiety and the regulation of cortisol reactivity. Anxiety Stress Coping Int J. 2006;19(1):81-92.
52. Thayer JF, Brosschot JF. Psychosomatics and psychopathology: Looking up and down from the brain. Psychoneuroendocrinology. 2005;30(10):1050-8.

53. Li Z, Snieder H, Su S, Ding X, Thayer JF, Treiber FA, et al. A longitudinal study in youth of heart rate variability at rest and in response to stress. Int J Psychophysiol. 2009;73(3):212-7.

54. Lawler-Row KA, Karremans JC, Scott C, Edlis-Matityahou M, Edwards L. Forgiveness, physiological reactivity and health: The role of anger. Int J Psychophysiol. 2008;68(1):51-8.

55. Japundzic N, Grichois ML, Zitoun P, Laude D, Elghozi JL. Spectral analysis of blood pressure and heart rate in conscious rats: Effects of autonomic blockers. J Auton Nerv Syst. 1990;30(2):91-100.

56. Randall DC, Brown DR, Raisch RM, Yingling JD, Randall WC. SA nodal parasympathectomy delineates autonomic control of heart rate power spectrum. Amer J Physiol-Heart and Circulatory Physiology. 1991;260(3):H985-8.

57. DelReyes PGA, Langewitz W, Mulder LJ, Roon A, Duschek S. The utility of low frequency heart rate variability as an index of sympathetic cardiac tone: A review with emphasis on a reanalysis of previous studies. Psychophysiology. 2013;50(5):477-87.

58. Eckberg DL. Sympathovagal balance: A critical appraisal. Circulation. 1997:96(9):3224-32

59. Goldstein DS, Bentho O, Park MY, Sharabi Y. Low-frequency power of heart rate variability is not a measure of cardiac sympathetic tone but may be a measure of modulation of cardiac autonomic outflows by barore flexes. Exper Physiol. 2011:96(12):1255-61.

60. Kleiger RE, Stein PK, Bigger JT. Heart rate variability: Measurement and clinical utility. Ann Noninvas Electrocardiol. 2005;10(1):88-101.

61. Malliani A, Pagani M, Montano N, Mela GS. Sympathovagal balance: A reappraisal. Circulation. 1998:98(23):2640a-3.

62. Malpas SC. Neural influences on cardiovascular variability: Possibilities and pitfalls. Am J Physiol Heart Circul Physiol. 2002;282(1):H6-20.

63. Parati G, Mancia G, Rienzo MD, Castiglioni P, Taylor JA, Studinger P. Cardiovascular variability is/is not an index of autonomic control of circulation. J App Physiol. 2006;101(2):690-1.

64. Bertsch K, Hagemann D, Naumann E, Schächinger H, Schulz A. Stability of heart rate variability indices reflecting parasympathetic activity. Psychophysiology. 2012:49(5):672-82.

65. Beauchaine T. Vagal tone, development and Gray's motivational theory: Toward an integrated model of autonomic nervous system functioning in psychopathology. Dev Psychopathol. 2001;13(2):183-214.

66. Butler EA, Wilhelm FH, Gross JJ. Respiratory sinus arrhythmia, emotion and emotion regulation during social interaction. Psychophysiology. 2006;43(6):612 22.

67. Porges SW. The polyvagal perspective. Biol Psych. 2007;74(2):116-43.

68. Jennings JR, Sheu LK, Kuan DCH, Manuck SB, Gianaros PJ. Resting state connectivity of the medial prefrontal cortex ovaries with individual differences in high-frequency heart rate variability. Psychophysiology. 2016;53(4):444-54.

Cite this article: Eaton KW, Ferrari TM. Heart Rate Variability During an Internal Family Systems Approach to Self-Forgiveness. Int J Clin Exp Physiol. 2020;7(2):52-7. 